\title{
Photoluminescence of Hexagonal ZnO Nanorods Hydrothermally Grown on Zn Foils in KOH Solutions with Different Values of Basicity
}

\author{
Nuengruethai Ekthammathat, ${ }^{1}$ Titipun Thongtem, ${ }^{1,2}$ \\ Anukorn Phuruangrat, ${ }^{3}$ and Somchai Thongtem ${ }^{2,4}$ \\ ${ }^{1}$ Department of Chemistry, Faculty of Science, Chiang Mai University, Chiang Mai 50200, Thailand \\ ${ }^{2}$ Materials Science Research Center, Faculty of Science, Chiang Mai University, Chiang Mai 50200, Thailand \\ ${ }^{3}$ Department of Materials Science and Technology, Faculty of Science, Prince of Songkla University, Hat Yai, Songkhla 90112, Thailand \\ ${ }^{4}$ Department of Physics and Materials Science, Faculty of Science, Chiang Mai University, Chiang Mai 50200, Thailand
}

Correspondence should be addressed to Titipun Thongtem; ttpthongtem@yahoo.com and

Anukorn Phuruangrat; phuruangrat@hotmail.com

Received 18 November 2012; Revised 19 February 2013; Accepted 25 February 2013

Academic Editor: Yun Zhao

Copyright (C) 2013 Nuengruethai Ekthammathat et al. This is an open access article distributed under the Creative Commons Attribution License, which permits unrestricted use, distribution, and reproduction in any medium, provided the original work is properly cited.

\begin{abstract}
Aligned hexagonal $\mathrm{ZnO}$ nanorods on pure $\mathrm{Zn}$ foils were hydrothermally synthesized in $30 \mathrm{~mL}$ solutions containing $0.05-0.50 \mathrm{~g}$ $\mathrm{KOH}$. The products were characterized by X-ray diffraction (XRD), scanning electron microscopy (SEM), transmission electron microscopy (TEM), and photoluminescence (PL) spectroscopy. In this research, wurtzite hexagonal ZnO nanorods grown along the [002] direction with green light emission at $541 \mathrm{~nm}$ caused by singly ionized oxygen vacancies inside were detected.
\end{abstract}

\section{Introduction}

One-dimensional (1D) semiconducting materials are able to be used for a number of potential applications in short wavelength optical, nanoelectronic, and optoelectronic devices due to their tunable electronic and optoelectronic properties controlled by morphologies and dimensions [1-3]. Compared to two-dimensional (2D), three-dimensional (3D), and zerodimensional (0D) nanostructures, the 1D nanostructure has unique characteristic: large aspect ratio, single crystalline structure, and oriented growth [3]. Zinc oxide is an important low-cost II-VI basic semiconductor with $3.37 \mathrm{eV}$ wide band gap and strong exciton binding energy of $60 \mathrm{meV}$ at room temperature [4-7]. It possesses unique catalytic, electrical, optoelectronic, and photochemical propertiesvery interesting for a number of potential applications as room-temperature UV lasers, sensors, light-emitting diodes, optical switches, solar cells, and photocatalysis due to its low dielectric constant, high chemical stability, good photoelectric, and piezoelectric behaviors $[4,6,8]$.
In the paper, hexagonal $\mathrm{ZnO}$ nanorods on $\mathrm{Zn}$ foils were hydrothermally synthesized in solutions containing $0.05-0.50 \mathrm{~g} \mathrm{KOH}$ at $120^{\circ} \mathrm{C}$. Their phase, morphology, and photoluminescence were investigated and discussed in more details.

\section{Experimental Procedure}

Reagents of the research were of analytical grade and used without further purification. The hexagonal prism $\mathrm{ZnO}$ nanorods were grown on $\mathrm{Zn}$ foils by the following. Several $10 \times 10 \mathrm{~mm}$ square $\mathrm{Zn}$ foils with $0.25 \mathrm{~mm}$ thick were cleaned with deionized water and absolute alcohol in an ultrasound bath and put in $30 \mathrm{~mL}$ of $0.05,0.10,0.20,0.30,0.40$, and $0.50 \mathrm{~g}$ $\mathrm{KOH}$ aqueous solutions, containing 1, 2, 4, 6, 8, and 10 times of $\mathrm{KOH}$ in sequence. All of the solutions and zinc foils were transferred into $50 \mathrm{~mL}$ Teflon-lined stainless steel autoclaves, which were tightly closed, heated at $120^{\circ} \mathrm{C}$ in a laboratory electric oven for $24 \mathrm{~h}$, and naturally cooled to room temperature. In the end, the zinc foils were thoroughly rinsed by 


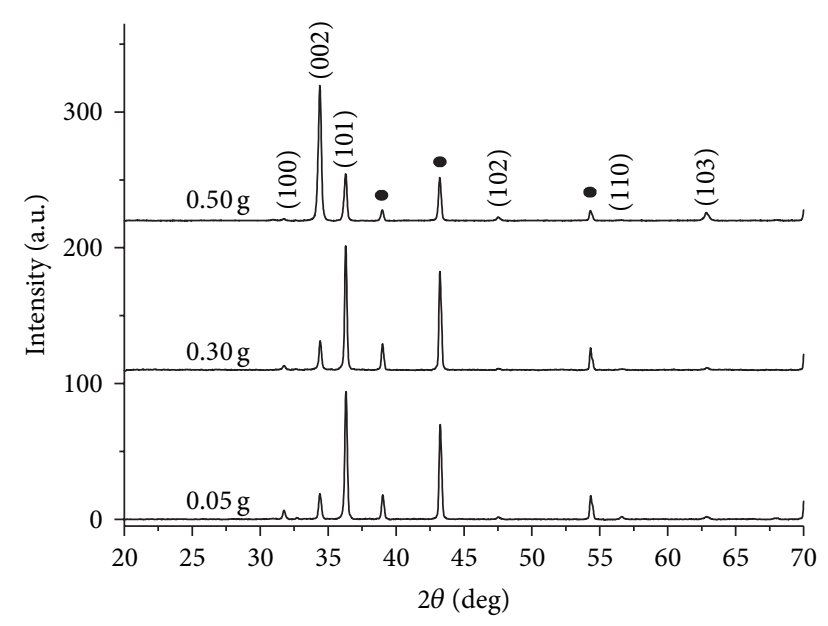

- Zn foil

(a)

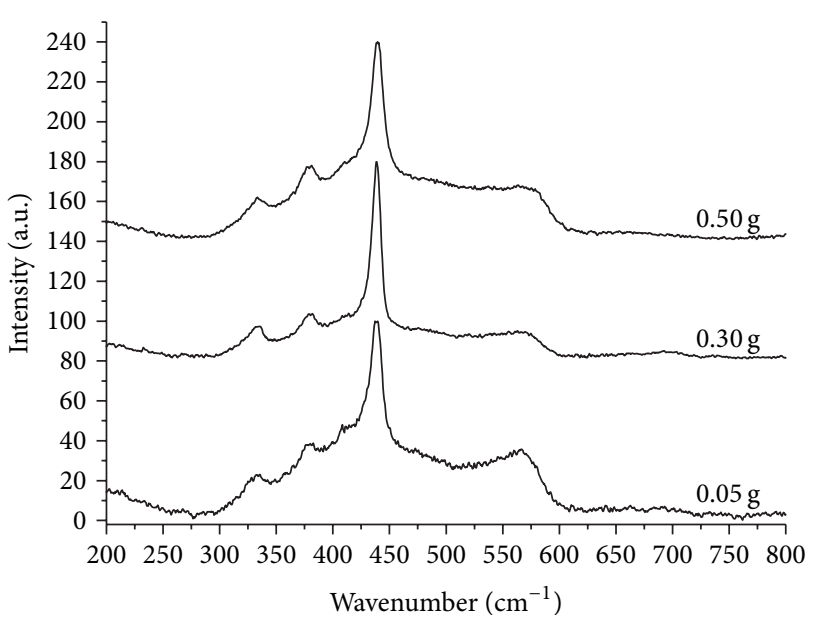

(b)

FIGURE 1: (a) XRD patterns and (b) Raman spectra of the assynthesized $\mathrm{ZnO}$ in $30 \mathrm{~mL}$ solutions containing 1 ( $0.05 \mathrm{~g}), 6$ (0.30 g) and 10 times $(0.50 \mathrm{~g})$ of $\mathrm{KOH}$.

deionized water several times and alcohol, and dried at $70^{\circ} \mathrm{C}$ in an electric oven for $12 \mathrm{~h}$ for further characterization.

X-ray diffraction (XRD) operated on Philips X'Pert MPD $\mathrm{X}$-ray diffractometer with $\mathrm{Cu} \mathrm{K}_{\alpha}$ radiation in the $2 \theta$ of $20-70$ deg with a scanning rate of 0.02 deg per step and Raman spectroscopy on T64000 HORIBA Jobin Yvon at $50 \mathrm{~mW}$ Ar Laser with $514.5 \mathrm{~nm}$ wavelength were used to determine phase, crystalline degree, purity, and vibration modes. Their morphologies were characterized by scanning electron microscopy (SEM, JEOL JSM-6335F) with an accelerating voltage of $15 \mathrm{kV}$ across the $\mathrm{LaB}_{6}$ cathode. Their nanostructures and growth direction were further investigated by transmission electronic microscopy (TEM) and selected area electronic diffraction (SAED) on a JEOL JEM-2010 TEM at $200 \mathrm{kV}$ with $\mathrm{LaB}_{6}$ gun. At the end, optical properties of the products were analyzed by a LS50B Perkin Elmer fluorescence spectrometer in the wavelength range of $450-700 \mathrm{~nm}$.

\section{Results and Discussion}

Figure 1(a) exhibits typical XRD patterns of the as-grown $\mathrm{ZnO}$ on $\mathrm{Zn}$ foils, revealing that all diffraction peaks were explicable in term of wurtzite $\mathrm{ZnO}$ structure with $a=b=$ $3.251 \AA$ and $c=5.208 \AA$ (JCPDS No. 36-1451) [9]. Sharp diffraction peaks indicate good crystalline degree of the assynthesized crystals without other impurities detection.

Degree of $c$ orientation of the as-synthesized $\mathrm{ZnO}$ samples was explained by the relative texture coefficient (TC) $[10,11]$ of the (002) peak calculated using the formula

$$
\mathrm{TC}_{002}=\frac{\left(I_{002} / I_{002}^{0}\right)}{\left[I_{002} / I_{002}^{0}+I_{100} / I_{100}^{0}\right]}
$$

$\mathrm{TC}_{002}$ is the relative texture coefficient of the (002) over (100) diffraction peaks. $I_{002}$ and $I_{100}$ are the measured diffraction intensities of the (002) and (100) peaks, including the corresponding $I_{002}^{0}$ and $I_{100}^{0}$ values of the randomly oriented standard powder, respectively. For randomly crystallographic orientation, the texture coefficient of $\mathrm{ZnO}$ is 0.5 . In the solution containing $0.50 \mathrm{~g} \mathrm{KOH}$, calculated $\mathrm{TC}_{002}$ was 0.86 , which supported the preferential orientation of the as-synthesized $\mathrm{ZnO}$ nanorods grown along the [002] direction on the $\mathrm{Zn}$ foil.

Wurtzite $\mathrm{ZnO}$ structure belongs to $\mathrm{C}_{6 v}^{4}\left(\mathrm{P}_{3} \mathrm{mc}\right)$ space group with two formula units per primitive cell, and all atoms occupy the $\mathrm{C}^{3 v}$ sites. Group theory of wurtzite $\mathrm{ZnO}$ structure predicts eight sets of phonon modes: $A_{1}+E_{1}+$ $2 \mathrm{E}_{2}$ (Raman active), $2 \mathrm{~B}_{2}$ (Raman silent), and $\mathrm{A}_{1}+\mathrm{E}_{1}$ (IR active). Moreover, the $A_{1}$ and $E_{1}$ symmetry are split into longitudinal $(\mathrm{L})$ and transverse $(\mathrm{T})$ optical $(\mathrm{O})$ components due to the macroscopic electric fields associated with the LO phonons. Figure 1(b) shows Raman spectra of the assynthesized $\mathrm{ZnO}$ nanorods. They show a dominant peak of typical characteristic of the wurtzite $\mathrm{ZnO}$ structure at $439 \mathrm{~cm}^{-1}$, assigned to be the optical phonon $\mathrm{E}_{2 \mathrm{H}}$ mode. The weak peak at $332 \mathrm{~cm}^{-1}$ was assigned to be the secondorder Raman scattering arising from the zone/zero boundary phonons $\mathrm{E}_{2 \mathrm{H}}-\mathrm{E}_{2 \mathrm{~L}}$ of multiphonon process, while the Raman peak at $379 \mathrm{~cm}^{-1}$ is attributed to $A_{1}$ symmetry with the TO mode. Furthermore, Raman spectra of $\mathrm{ZnO}$ samples at $567 \mathrm{~cm}^{-1}$ are a contribution of the $\mathrm{E}_{1}(\mathrm{LO})$ mode which is directly associated with oxygen vacancies. The stronger $E_{1}$ (LO) mode indicates the presence of higher oxygen vacancies inside [5, 12-14].

SEM images as shown in Figure 2 were investigated on surfaces of $\mathrm{Zn}$ foils after hydrothermal treatment in $30 \mathrm{~mL}$ solutions containing $1(0.05 \mathrm{~g}), 2(0.10 \mathrm{~g}), 4(0.20 \mathrm{~g}), 6$ ( $0.30 \mathrm{~g})$, $8(0.40 \mathrm{~g})$, and 10 times $(0.50 \mathrm{~g})$ of $\mathrm{KOH}$. An interesting feature of the nanostructures grown on the bottom surfaces exhibited the presence of aligned nanorods of $\mathrm{ZnO}$ with the diameter ranging from $400 \mathrm{~nm}$ to $700 \mathrm{~nm}$ without the detection of other nanostructures. The lengths of the $\mathrm{ZnO}$ nanorods are in the range of several micrometers to even longer than $5-7 \mu \mathrm{m}$. These nanorods were enlarged and lengthened in sequence with an increase in the degree of basicity. The inset of Figure 2(f) demonstrates the hexagonal 


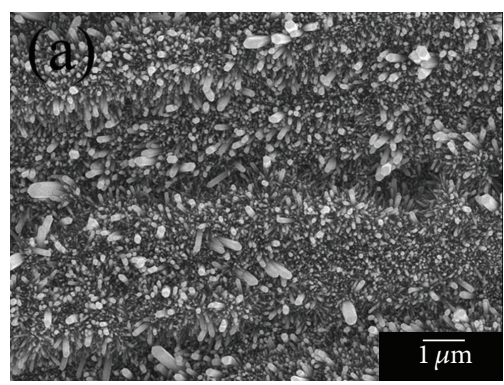

(a)

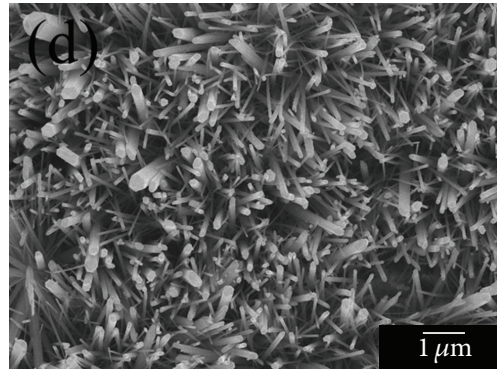

(d)

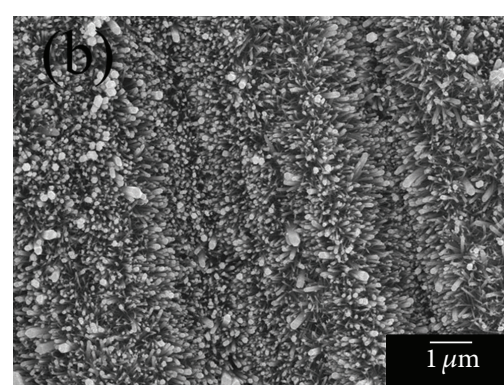

(b)

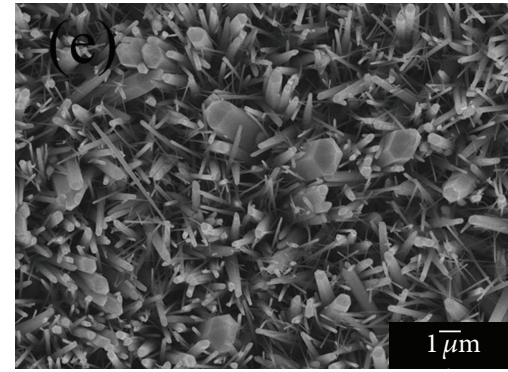

(e)

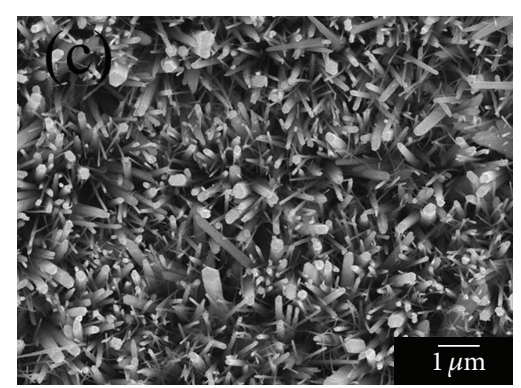

(c)

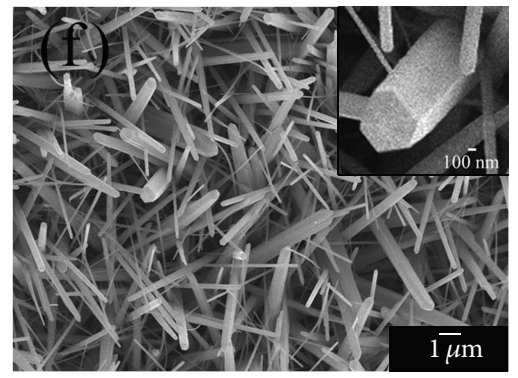

(f)

Figure 2: SEM images of the as-synthesized ZnO samples in $30 \mathrm{~mL}$ solutions containing (a) 1 (0.05 g), (b) 2 (0.10 g), (c) 4 (0.20 g), (d) 6 $(0.30 \mathrm{~g}),(\mathrm{e}) 8(0.40 \mathrm{~g})$, and (f) 10 times $(0.50 \mathrm{~g})$ of $\mathrm{KOH}$.

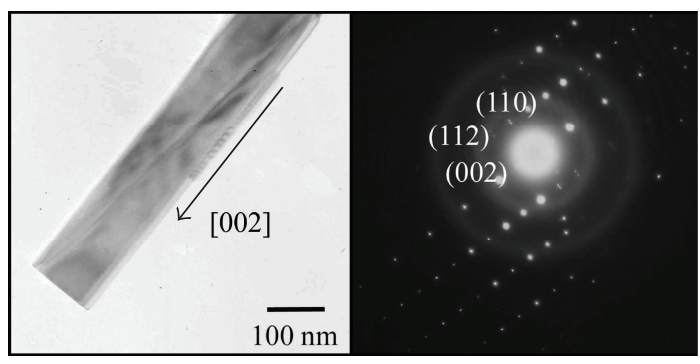

FIGURE 3: TEM image and SAED pattern of hexagonal $\mathrm{ZnO}$ nanorod in $30 \mathrm{~mL}$ solution containing 10 times $(0.50 \mathrm{~g})$ of $\mathrm{KOH}$.

$\mathrm{ZnO}$ nanorod which was fully grown on $\mathrm{Zn}$ foil in the solution containing $0.50 \mathrm{~g} \mathrm{KOH}$.

The hexagonal $\mathrm{ZnO}$ nanorods were also characterized through TEM and SAED (Figure 3). TEM image reveals a single hexagonal $\mathrm{ZnO}$ nanorod with smooth surface and the preferred growth in the [002] direction. It shows the SAED pattern of bright spots corresponding to hexagonal wurtzite $\mathrm{ZnO}[9]$.

Based on the previous discussion, mechanism of the growth and morphology of $\mathrm{ZnO}$ nanostructure can be proposed as follows:

$$
\begin{gathered}
\mathrm{Zn}+2 \mathrm{H}_{2} \mathrm{O}+2 \mathrm{OH}^{-} \longrightarrow \mathrm{Zn}(\mathrm{OH})_{4}{ }^{2-}+\mathrm{H}_{2} \\
\mathrm{Zn}(\mathrm{OH})_{4}{ }^{2-} \longrightarrow \mathrm{ZnO}+\mathrm{H}_{2} \mathrm{O}+2 \mathrm{OH}^{-}
\end{gathered}
$$

The formation of $\mathrm{Zn}(\mathrm{OH})_{4}{ }^{2-}$ ions from $\mathrm{Zn}^{2+}$ and $\mathrm{OH}^{-}$ ions by a hydrothermal reaction is a key role in the formation of hexagonal wurtzite $\mathrm{ZnO}$ nanorods. The primary $\mathrm{ZnO}$ nanoparticles began to nucleate on $\mathrm{Zn}$ foil by the dissolution of $\mathrm{Zn}$ atoms into the solution and the cause of concentration gradient of $\mathrm{Zn}^{2+}$. The intrinsic electric fields of the polar $\mathrm{ZnO}$ lattice could be responsible for further growth of $\mathrm{ZnO}$ crystals, described as alternating planes of $\mathrm{Zn}^{2+}$ and $\mathrm{O}^{2-}$, stacked along the $c$-axis. The oppositely charged ions produced positively charged and negatively charged surfaces, resulting in polarization along the $c$-axis. The preferred $c$-axis orientation of $\mathrm{ZnO}$ nanostructure is driven by electrostatic interaction between the polar charges to minimize surface energy. Finally, $\mathrm{ZnO}$ nanorods grew on $\mathrm{Zn}$ foil as substrate [15].

The main emission of $\mathrm{ZnO}$ nanorods can be assigned as the recombination of free excitons. Other peaks probably originated from position of band-edge emission of $\mathrm{ZnO}$ of relatively large dimensions with different concentration of native defects [16]. It is well known that visible photoluminescence mainly originates from defect states of $\mathrm{Zn}$ interstitials, zinc vacancies, and oxygen vacancies [17]. Photoluminescence (PL) of $\mathrm{ZnO}$ nanorods grown on $\mathrm{Zn}$ foils was investigated using excitation wavelength of $214 \mathrm{~nm}$ at room temperature as shown in Figure 4. PL spectrum of hexagonal $\mathrm{ZnO}$ nanorods using $0.50 \mathrm{~g} \mathrm{KOH}$ shows the highest strong green light emission at $541 \mathrm{~nm}$, due to the singly ionized oxygen vacancies of $\mathrm{ZnO}$, in accordance with other reports [16-18].

\section{Conclusions}

In summary, densely aligned hexagonal $\mathrm{ZnO}$ nanorods on $\mathrm{Zn}$ foils were synthesized by a $120^{\circ} \mathrm{C}$ and $24 \mathrm{~h}$ hydrothermal reaction. The XRD, SEM, and TEM analyses showed that the 


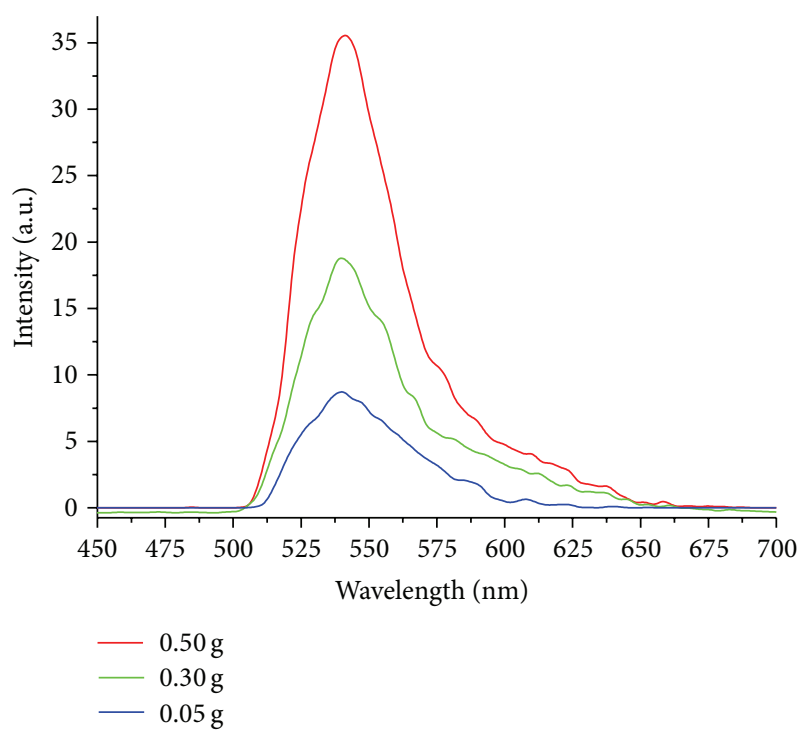

Figure 4: PL spectra of the as-synthesized $\mathrm{ZnO}$ in $30 \mathrm{~mL}$ solutions containing $1(0.05 \mathrm{~g}), 6(0.30 \mathrm{~g})$, and 10 times $(0.50 \mathrm{~g})$ of $\mathrm{KOH}$.

as-synthesized products were pure wurtzite $\mathrm{ZnO}$ nanorods with uniform hexagonal structure of 400-700 nm diameter and 5-7 $\mu \mathrm{m}$ long. Room temperature PL spectrum of the $\mathrm{ZnO}$ nanorods exhibited one strong green light emission at $541 \mathrm{~nm}$ due to the singly ionized oxygen vacancies inside.

\section{Acknowledgments}

The authors wish to thank the Thailand's Office of the Higher Education Commission for providing financial support through the National Research University (NRU) Project for Chiang Mai University (CMU) and the Human Resource Development Project in Science Achievement Scholarship of Thailand (SAST) and the Thailand Research Fund (TRF) for providing financial support through the TRF Research Grant BRG5380020, including the Graduate School of CMU through a general support.

\section{References}

[1] L. Z. Pei, H. S. Zhao, W. Tan, H. Y. Yu, Y. W. Chen, and Q. F. Zhang, "Single crystalline $\mathrm{ZnO}$ nanorods grown by a simple hydrothermal process," Materials Characterization, vol. 60, no. 9, pp. 1063-1067, 2009.

[2] Z. Li, X. Huang, J. Liu, Y. Li, and G. Li, "Morphology control and transition of $\mathrm{ZnO}$ nanorod arrays by a simple hydrothermal method," Materials Letters, vol. 62, no. 10-11, pp. 1503-1506, 2008.

[3] X. Wu, H. Chen, L. Gong, F. Qu, and Y. Zheng, "Low temperature growth and properties of $\mathrm{ZnO}$ nanorod arrays," Advances in Natural Sciences, vol. 2, Article ID 035006, 2011.

[4] H. Zhang, J. Feng, J. Wang, and M. Zhang, "Preparation of ZnO nanorods through wet chemical method," Materials Letters, vol. 61, no. 30, pp. 5202-5205, 2007.

[5] J. H. Yang, J. H. Zheng, H. J. Zhai, L. L. Yang, J. H. Lang, and M. Gao, "Growth mechanism and optical properties of
$\mathrm{ZnO}$ nanosheets by the hydrothermal method on Si substrates," Journal of Alloys and Compounds, vol. 481, no. 1-2, pp. 628-631, 2009.

[6] X. Ren, D. Han, D. Chen, and F. Tang, "Large-scale synthesis of hexagonal cone-shaped $\mathrm{ZnO}$ nanoparticles with a simple route and their application to photocatalytic degradation," Materials Research Bulletin, vol. 42, no. 5, pp. 807-813, 2007.

[7] S. Suwanboon, R. Tanattha, and R. Tanakorn, "Fabrication and properties of nanocrystalline zinc oxide thin film prepared by sol-gel method," Songklanakarin Journal of Science and Technology, vol. 30, no. 1, pp. 65-69, 2008.

[8] D. Wang, C. Song, Z. Hu, W. Chen, and X. Fu, "Growth of ZnO prisms on self-source substrate," Materials Letters, vol. 61, no. 1, pp. 205-208, 2007.

[9] Powder Diffract, File, JCPDS Internat. Centre Diffract. Data, PA, 19073-3273, U.S.A, 2001.

[10] J. H. Park, P. Muralidharan, and D. K. Kim, "Solvothermally grown $\mathrm{ZnO}$ nanorod arrays on (101) and (002) single- and polycrystalline Zn metal substrates," Materials Letters, vol. 63, no. 12, pp. 1019-1022, 2009.

[11] F. Li, Z. Li, and F. J. Jin, "Structural and luminescent properties of $\mathrm{ZnO}$ nanorods," Materials Letters, vol. 61, no. 8-9, pp. 18761880, 2007.

[12] L. 1. Yang, J. H. Yang, D. D. Wang et al., "Photoluminescence and Raman analysis of $\mathrm{ZnO}$ nanowires deposited on $\mathrm{Si}(100)$ via vapor-liquid-solid process," Physica E, vol. 40, no. 4, pp. 920923, 2008.

[13] O. Lupan, L. Chow, L. K. Ono et al., "Synthesis and characterization of Ag- or Sb-doped $\mathrm{ZnO}$ nanorods by a facile hydrothermal route," Journal of Physical Chemistry C, vol. 114, no. 29, pp. 12401-12408, 2010.

[14] S. J. Chen, Y. C. Liu, Y. M. Lu, J. Y. Zhang, D. Z. Shen, and X. W. Fan, "Photoluminescence and Raman behaviors of $\mathrm{ZnO}$ nanostructures with different morphologies," Journal of Crystal Growth, vol. 289, no. 1, pp. 55-58, 2006.

[15] J. Y. Kim, H. Jeong, and D. J. Jang, "Hydrothermal fabrication of well-ordered $\mathrm{ZnO}$ nanowire arrays on $\mathrm{Zn}$ foil: room temperature ultraviolet nanolasers," Journal of Nanoparticles Research, vol. 13, no. 12, pp. 6699-6706, 2011.

[16] W. Li, Y. Sun, and J. Xu, "Controllable hydrothermal synthesis and properties of $\mathrm{ZnO}$ hierarchicalmicro/nanostructures," Nano-Micro Letters, vol. 4, no. 2, pp. 98-102, 2012.

[17] Y. J. Gao, W. C. Zhang, X. L. Wu et al., "Hydrothermal selfassembling of $\mathrm{ZnO}$ nanorods into sphere-like superstructures and their optical characteristics," Applied Surface Science, vol. 255, no. 5, pp. 1982-1987, 2008.

[18] G. Z. Wang, N. G. Ma, C. J. Deng et al., "Large-scale synthesis of aligned hexagonal $\mathrm{ZnO}$ nanorods using chemical vapor deposition," Materials Letters, vol. 58, no. 16, pp. 2195-2198, 2004. 

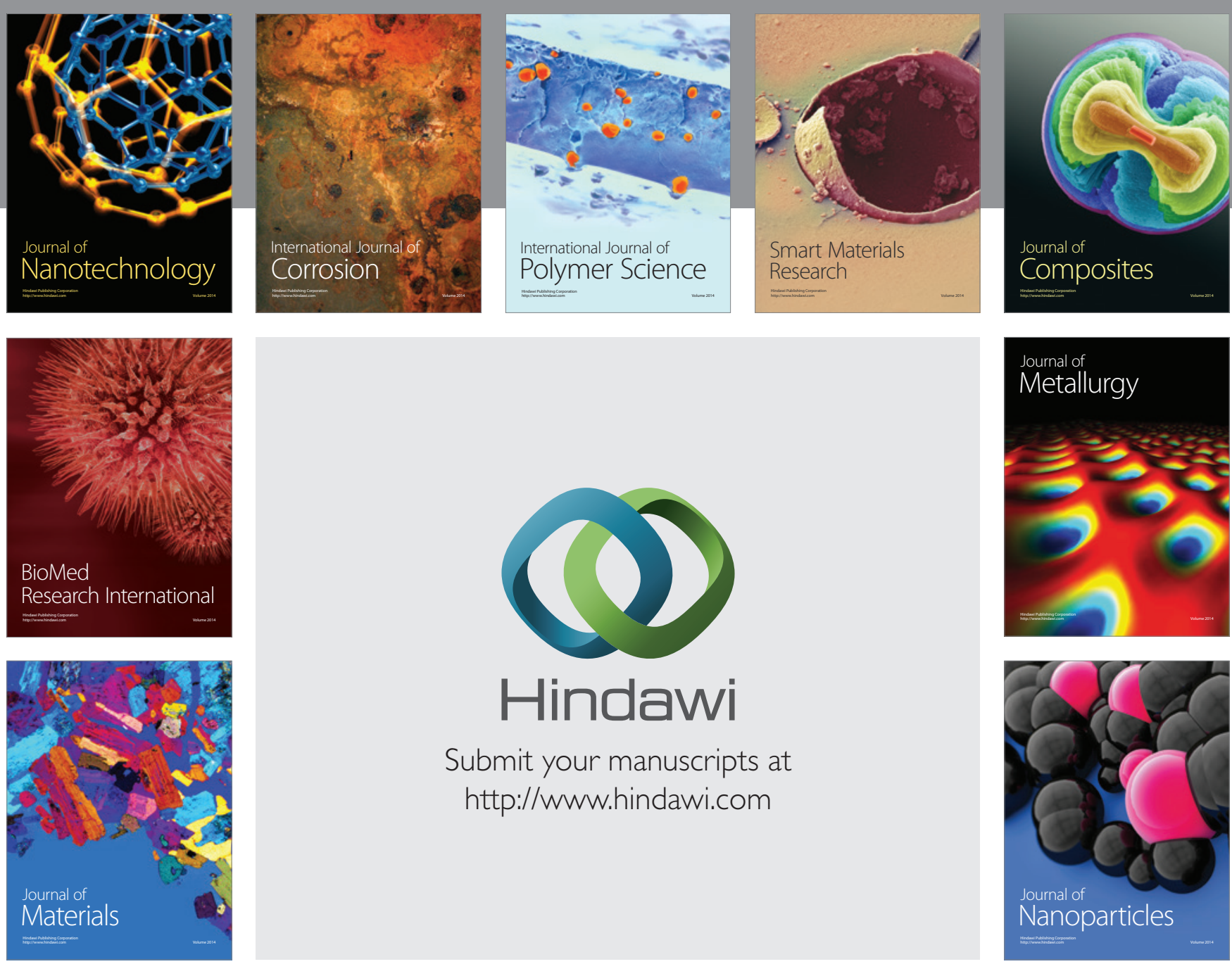

Submit your manuscripts at http://www.hindawi.com
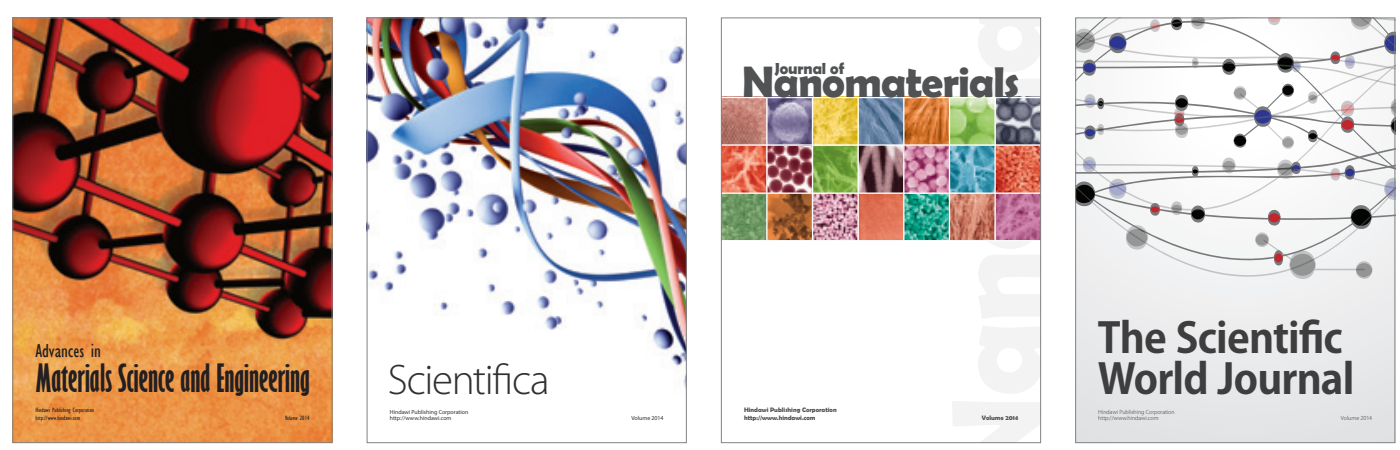

\section{The Scientific World Journal}
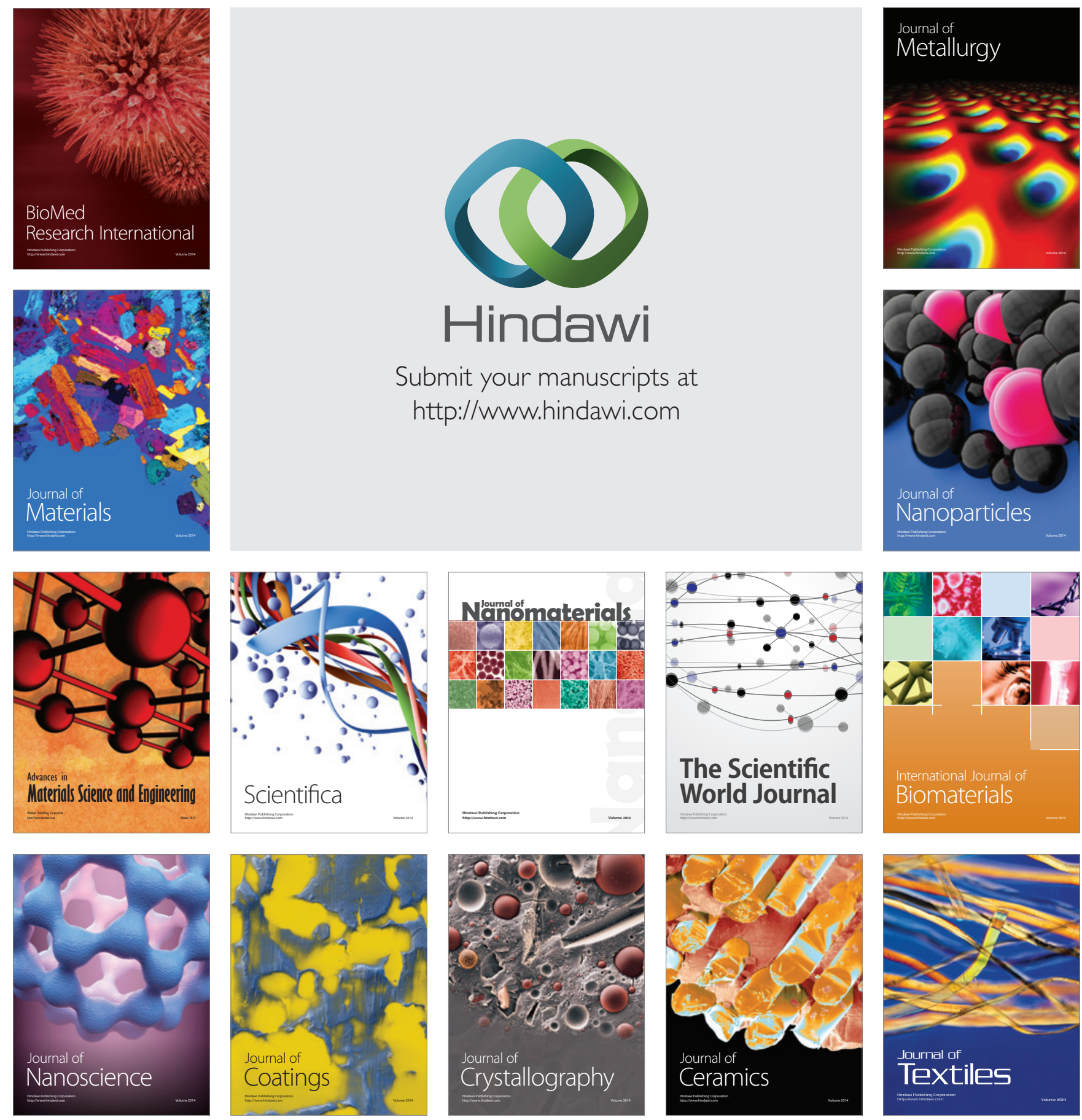